\title{
On the osteology of a distinctive specie of the genus Leptodactylus: Leptodactylus laticeps (Boulenger, 1917) (Anura, Leptodactylidae)
}

\author{
MARÍA LAURA PONSSA. \\ Instituto de Herpetología. Fundación Miguel Lillo. Miguel Lillo 251. 4000- San Miguel de Tucumán. Argen-
} tina.E-mail: mlponssa@arnet.com.ar

\begin{abstract}
The osteology of Leptodactylus laticeps is described. This species is the most distinctive member of the pentadactylus species group, and possibly of the genus Leptodactylus, based on external morphology, skin secretions and some aspects of its life history. This paper notes some characters that differ from or were previously overlooked in, description of the Leptodactylus. These are: 1) arrangement cotylar type II, 2) sacral diapophyses expanded, 3) nasals contiguos or in contact with frontoprietals, and 4) an anterior ramus parasphenoid which can or cannot reach the palatines. Some characters could be useful for species diagnoses and/or phylogenetic studies, such as elongation of the pars facialis of maxilla, maxillary teeth found almost reaching quadratojugal or extending beyond quadratojugal, nasals with posterolateral projections very prominent, nasals almost or in contact with each other; high number of vomerine teeth, tip of palatines not acute, and an alary process of premaxilla which is oriented slightly postero-dorsally.
\end{abstract}

Key words: Leptodactylus laticeps, osteology

\section{Introduction}

Leptodactylus laticeps is one of the 64 species of Leptodactylus currently recognized (Frost 2004) . This species is the most distinctive member of the pentadactylus species group based on external morphology (Heyer 1979). It is characterized by a skin pattern that no other member of the group possesses. The dorsum has a warning color, with bright red-black spots on a whitish background. In the preserved specimens, the black squares have cream areas within and are separated by white areas (Heyer 1979). Also skin secretions can provoke allergic rections, likely due to a high content of histamine derivatives (Cei 1980), unknown in other species of the pentadactylus group. Leptodactylus laticeps inhabits the deep holes created by social rodents (Lagostomus). 
These characteristics makes this species unique among the pentadactylus species group and one of the most curious in the genus Leptodactylus. The logical consequence of this fact is to question if this uniqueness is also present in the internal anatomy pattern.

The pentadactylus species group was first studied by Heyer (1979), who recognized 11 species. Since then new species have been described (e.g. Heyer 1995; McCranie et al. 1980), but in all the cases the available information used in the phylogenetic studies was limited to external morphology. Actually Leptodactylus laticeps is a rare frog endemic to the Chacoan areas, and one whose evolutionary relationships remain unknown. The objectives of this paper are (1) to provide a detail description of the osteology, to determinate if the particular characteristics of its external morphology and life history, which distinguish this species from others of the group, are also present in its internal anatomy; and (2) to compare the obtained information with the osteologycal characterization previously made in the genus.

\section{Material and methods}

The study is based on 3 females, 3 males and one juvenile. Two specimens were from Paraguay and 5 from Argentina. Four specimens were cleared and stained following Wassersugs (1976) protocol. These specimens are FML (Fundación Miguel Lillo) 09050, FML 05250, FML 00829, and FML 16245. The other specimens, USNM (United State Natural Museum) 227605, and USNM 253711-12, were dry skeleton preparations. The terminology for cranial and postcranial osteology follows Heyer (1975), Lynch (1971), Trueb $(1973 ; 1993)$ and Trueb et al. (2000). Terminology of fingers and carpal osteology follows Fabrezi (1992) and laryngeal morphology follows Trewavas (1933). The measurements are given in Table 1.

\section{Results}

\section{Cranial Osteology of Adults}

(Fig. 1A and B)

\section{Mandible (Fig. 1E)}

The mentomeckelian is fused to dentary, it is L-shaped, with the shorter rami parallel to the medial plane of the skull.

The dentary is narrow and anteriorly curved. It covers outer surface of Meckel's cartilage.

The angular is long and correspond to the largest component of the mandible. It does not reach mentomeckelian; covers the inner surface of Meckel's cartilage. The coronoid process is trapezoidal. 
TABLE 1. Measurements in mm of adults specimen of Leptodactylus laticeps.

\begin{tabular}{|c|c|}
\hline Character & Mean $(n=6)$ \\
\hline Width skull = maximum distance between both sides of the mandible arc & 36.43 \\
\hline $\begin{array}{l}\text { Maximum length of skull = from the right condyle to the premaxilla of the same } \\
\text { side. }\end{array}$ & 28.23 \\
\hline Frontoparietals length & 13.25 \\
\hline Nasals length $=$ from the anterior vertex to the extern posterior vertex & 11.30 \\
\hline Nasals width $=$ from the posterior extern vertex to posterior intern angle & 10.08 \\
\hline Quadratojugal length & 11.32 \\
\hline Zygomatic ramus of squamosal length & 5.02 \\
\hline Otic ramus of squamosal length & 3.08 \\
\hline Descendent ramus of squamosal length & 9.96 \\
\hline Maximum width of parasphenoid & 4 \\
\hline Extreme of parasphenoid width & 1.9 \\
\hline Parasphenoid length & 16.51 \\
\hline Cultriform process of parasphenoid length & 12.33 \\
\hline Alae of parasphenoids width= distance between the extern angles of alae & 2.42 \\
\hline Alae of parasphenoid length & 15.77 \\
\hline Diameter of the orbit, the bigger one & 13.03 \\
\hline Width of the base of the cultriform process of parasphenoid & 2.87 \\
\hline Middle side of palatine width & 1.82 \\
\hline Palatine length & 10.19 \\
\hline Extern extreme of palatines width & 2.88 \\
\hline Intern extreme of palatines width & 0.79 \\
\hline Media ramus of pterygoid length & 6.75 \\
\hline Posterior ramus of pterygoid length & 8.79 \\
\hline Occipital condyles length & 3.25 \\
\hline Occipital condyles width & 1.66 \\
\hline Palatine process of premaxilla length & 2.15 \\
\hline Width of the base of alary process of premaxilla & 1.54 \\
\hline Maximum length of premaxilla & 4.44 \\
\hline Inferior mandibule length & 32.51 \\
\hline Angular length & 30.06 \\
\hline Clavicles length & 11.03 \\
\hline Coracoid length & 8.64 \\
\hline Scapula length & 10.76 \\
\hline Hyoid plate length & 14.29 \\
\hline
\end{tabular}

Width skull = maximum distance between both sides of the mandible arc

Descendent ramus of squamosal length $\quad 9.96$

Extreme of parasphenoid width

Cultriform process of parasphenoid length 12.33

Alae of parasphenoids width= distance between the extern angles of alae 2.42

Diameter of the orbit, the bigger one

Middle side of palatine width

Extern extreme of palatines width $\quad 2.88$

Intern extreme of palatines width

Media ramus of pterygoid length

Posterior ramus of pterygoid length

Occipital condyles length

Occipital condyles width

Width of the base of alary process of premaxilla

to be continued 
TABLE 1 (continued)

\begin{tabular}{lc}
\hline Character & Mean (n =6) \\
\hline Middle region of hyoid plate length & 5.31 \\
Hyoid width & 8.01 \\
Alary process width & 0.49 \\
Alary process of premaxilla length & 2.75 \\
Posterolateral process length & 9.79 \\
Vertebral column length & 62.05 \\
Transverse process of $3^{\circ}$ vertebra length & 7.63 \\
Extreme of transverse process of $3^{\circ}$ vertebra width & 2.92 \\
Width of the base of transverse process of $3^{\circ}$ vertebra & 1.62 \\
Extreme of sacral diapophyses width & 3.88 \\
Base of sacral diapophyses width & 2.02 \\
Diapophyses sacral length & 6.6 \\
Urostyle length & 29.99 \\
Ilial shaft length & 30.79 \\
Dorsal acetabular expansion length & 5.54 \\
Postacetabular expansion length & 4.74 \\
Ventral acetabular zone length & 4.88 \\
Diameter of the acetabular fossa & 6.2 \\
Humerus length & 25.20 \\
Tibiafibula length & 12.65 \\
\hline & 35.28 \\
tibiale-fibulare length & 34.11 \\
\hline
\end{tabular}

\section{Maxillary arcade}

The maxillary arcade is complete. The upper jaw consist of premaxillae, maxillae and quadratojugal.

The premaxillae are fused neither to each other nor with the maxillae. Each premaxilla bears 11 to 13 teeth. The lateral side articulates with the maxillae. The alary process is subrectangular with narrow base; it is perpendicular to the middle axis of the skull. This process is oriented slightly postero-dorsally, and it curves backwards; it does not contact with the nasals. The alary processes are parallel to each other or slightly convergent. The pars palatina is subrectangular, the palatine process beers a clear ridge.

Maxilla. The anterior tip bears a ventrolateral projection that overlies the premaxilla; whereas the narrow posterior tip overlaps with the quadratojugal. The teeth are conic, curved, and bicuspid. The maxillary teeth found almost reaching quadratojugal or 
extending beyond quadratojugal. Each maxillae bears from 43 to 61 teeth. The pars

facialis ends at the level of the palatines; it does not contact the nasals, however it presents a projection extending towards the nasals.

The quadratojugal is a completely ossified, rod-shaped, bone. It overlaps anteriorly with the maxilla and contacts posteriorly with the squamosal.

\section{Nasal capsule}

The septum nasi, tectum nasi and solum nasi are cartilaginous, but mineralized. The tectum nasi is anteriorly straight and posterior to the alary processes of the premaxillae.

\section{Endocranial braincase}

The endocranial braincase is complete, consisting of sphenethmoid, prootics, and exoccipitals, which are partially covered by the frontoparietals dorsally and the parasphenoid ventrally.

The sphenethmoid forms the floor, anterolateral walls and the edges of the roof of the braincase. It is ossified and it is often, but not always, in contact with the optic foramen. It is dorsally visible between the nasals and frontoparietals. The latero-posterior margins are convex. Dorsally the sphenetmoid overlaps with the posterior $1 / 3$ of the nasals; ventrally it overlaps with $1 / 3$ of the palatines, the anterior $2 / 3$ of the frontoparietals, and vomers. It is differentiated from the septum nasi and tectum nasi.

An orbitonasal foramen is visible, anterolaterally, and is enclosed by the sphenethmoid. The optic foramen can be completely enclosed by cartilage or by cartilage and the parasphenoid.

The prootics are fused with the exoccipitals, forming the posterior region of the braincase and each one contributes to the otic capsules. The prootics are not fused with frontoparietals. They lack dorsal ornamentation. The occipital canal is closed or not visible. Prootic foramen is ovoid, pyriform or circular and totally enclosed by bone. The oculomotor foramen is enclosed by the prootic and cartilage, or only by the cartilage, or by cartilage, parasphenoid and the prootic. The prootic foramen is enclosed by the prootic and cartilage.

Exoccipitals. These bones form the posteromedial walls of the otic capsules, the margins of the foramen magnum and the occipital condyle. There is osified cartilage between the exoccipitals. They are ventrally covered by the parasphenoid.

The occipital condyles are protuberant, separated, divergent to upward, and half-moon or semiovoid-shaped. They are located forward in relation to the plane that joins the posterior borders of the quadrates.

The jugular foramen is lateral to the occipital condyles, entering the posterior wall of the otic capsule. 


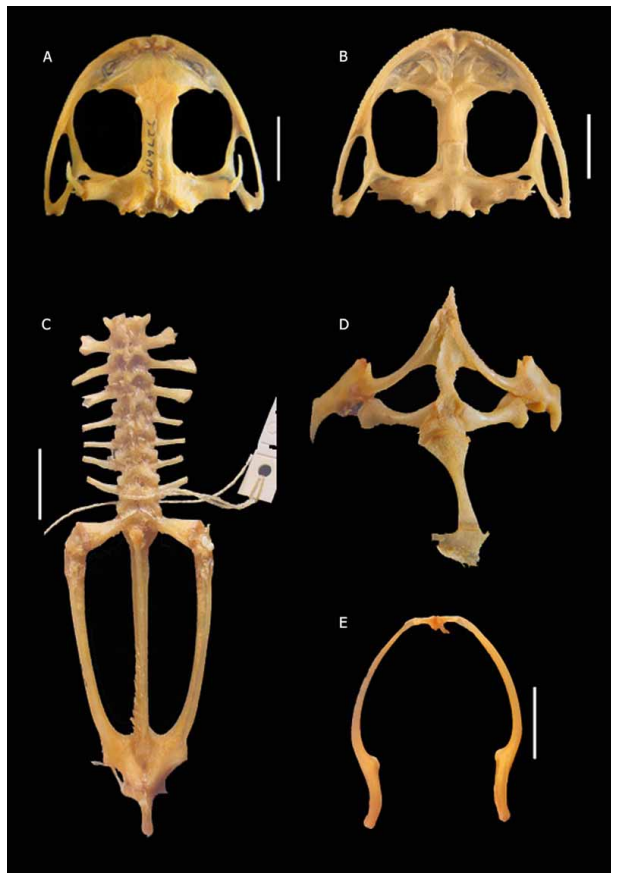

FIGURE 1. (A) Dorsal view of the skull of Leptodactylus laticeps; (B) Ventral view of the skull; (C) Vertebral column and pelvic girdle; (D) Pectoral Girdle; (E) Mandible. Bar $=1 \mathrm{~cm}$.

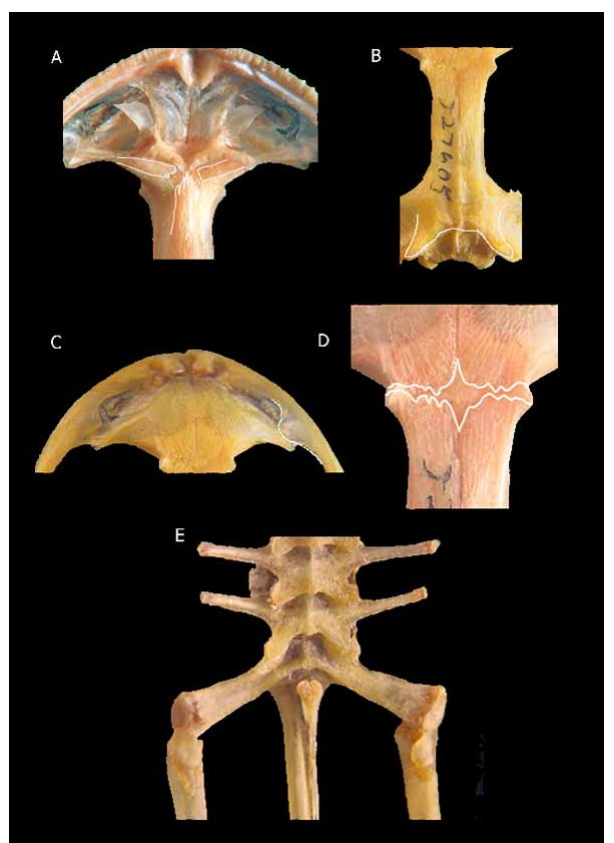

FIGURE 2. Details of some peculiar characters (A) Anterior ramus parasphenoid reach the palatines; interior extreme of palatines straigh; (B) Posterolateral projections very prominent; (C) Nasals contiguous or in contact through the length of its inner border; pars facialis of maxilla with a prolongation, which can contact or not with the nasals; (D) Nasals contiguos or in contact with frontoprietals; (E) Sacral diapophyses expanded. 
The pars externa plectri is approximately globe-shaped.

Plectrum. The pars interna plectri articulate with the operculum. It is completely ossified except a cartilaginous intern lobule. This cartilaginous area has a short, conic and curved upwards apophysis. The pars media plectri is a slightly curved, ossified stylus.

Operculum. The element is mineralized, elliptic, and externally convex. It almost completely covers the oval window. The opercular crest well developed.

\section{Dermal investing bones}

The frontoparietals are paired bones. The anterior extremes are straight or slightly acute. The external edges are straight and either parallel to each other. They are dorsally convex. The parietal-otic sides are expanded and rounded. Posteriorly they overlap the prootics, but they do not reach the foramen magnum. The posterolateral projections are distinctive, but relatively short. They do not contact the squamosal. They cover the sphenethmoid apparentely for half of its length, but in almost all the specimens one cannot determine the percentage of overlap because the sphenethmoid is almost not visible dorsally. The lateral margins are not fused with the otoccipital. The frontoparietal fenestra is completely covered by frontoparietals. The frontoparietal fenestra (only distinguishible in one specimen) is oval-shaped, with a posterior small "tongue"; it extends forward from the middle one-third of the skull.

The nasals are paired subtriangular bones, transversally oriented, superimposed on the sphenethmoid and with curved margins. They are contiguous or in contact through the length of its inner border. The extreme end of the maxilar process is acute. A small space separates the nasals from the oblique cartilage of the nasal capsule. The posterointernal angles of the nasals are contiguous or in contact with the frontoparietals. A diagonal ledge extends trough the maxilar process.

The parasphenoid is an unpaired, T-shaped bone. It is not fused with the subjacent bones. The cultriform process is long and not keeled and it has straight or curved edges that are anteriorly convergent. The cultriform process is rhomboidal, rectangular or ovalshaped and serrated anteriorly. The cultriform process rests on the sphenethmoid. In some specimens, the anterior border of the cultriform process reaches the level of the palatines, extending between them. The posteromedial process of the parasphenoid is acuminate and terminates well forward of the margin of the foramen magnum. The alae of the parasphenoid are not fused with the otoccipitals, their orientation deflects posteriorly, and they gradually expand to the extreme edge.

The edges of palatines are sharp without ornamentation or odontoids. The palatines have an inferior ridge. They are oriented perpendicular to the axial axis of the skull. One-third of their inner length overlaps with the sphenethmoid. The outer edge is expanded and contacts the pars palatina of the maxilla. The vomers cover the inner tips of palatines, which are separate from each other. 
The vomers are paired bones that overlap the sphenethmoid. They are separated or contiguous and are formed by a dentigerous process and three alae that constitute the anterior and medial margins of the choanae. The middle ramus is longer than the anterior and posterior rami. The angle between the anterior and middle alae is lesser than $90^{\circ}$, while the angle between the middle and posterior alae may be greater, equal or lesser than $90^{\circ}$. The tip of the anterior alae is acuminate and does not contact with either the maxilla or the premaxilla. Each dentigerous process has a curved transverse row of 10 to 17 teeth.

\section{Suspensorium}

Each pterygoid has well-developed anterior, medial and posterior rami. The anterior ramus is expanded anteriorly and articulates with the inner side of the maxilla; it does not reach the palatines. Both anterior rami are parallel to each other. The medial ramus and parasphenoid overlap and are in contact or not. The medial ramus rests on the prootic. The anterior and posterior rami are S-shaped. The posterior ramus is laminar, curved, and joins the quadratojugal-squamosal complex.

Squamosal. The zygomatic ramus is curved or straight and is subrectangular or subtriangular in shape. It does not contact the maxilla and does not have any process oriented towards the anterior extreme of the tympanic annulus. In dorsal view, the zygomatic rami of each squamosal are parallel.

The otic ramus is subrectangular or subtriangular and does not contact the frontoparietal. The otic ramus is shorter in length than the zygomatic ramus but it is wider than or as wide as the zygomatic ramus. The tip is uniformly broad and reaches or overlaps the border of crista parotica. The crista parotic is mineralized.

The descendent ramus has a medial canal. The inferior is expanded, forming an angle greater than $45^{\circ}$ with the horizontal plane of skull. The angle between the squamosal and maxilla less than $45^{\circ}$.

The tympanic annulus is dorsally opened, cartilaginous, and joined to the crista parotic.

Hyoid apparatus. The hyoid plate is cartilaginous, mineralized at the base of the alary, hyale, posterolateral and posteromedial processes. The margins are parallel. The hyoglossal sinus is deep. The limits between the hyoid plate and the hyoid processes are very distinct.

The alary processes are thin, perpendicular to the axial axis of the hyoid plate, with a distal expansion.

The hyales are thin, curved and of uniform width. The distal extremes are joined by cartilage with the otic capsule anteriorly and under the columella.

The posterolateral processes are thin. The base arises on the posterolateral side of the hyoid plate and is oriented postero-laterally. The posterior end extends well beyond the level of the posterior edge of the hyoid plate, and does not have a terminal expansion. 
Posteromedial processes. The posterior ends are cartilaginous. Both anterior and posterior ends are expanded. The area where they join to the plate is not bifurcate.

\section{Laryngeal cartilage}

The arytenoids consist of a pair of valve-shaped cartilages, subtriangular in shape in the lateral view.

The cricoid forms a complete pentagonal- circular ring. An esophageal process is differentiated, triangular or trapezoidal. The bronchial process is differentiated, and noticeably thin.

In females, the cricoids are thinner and the arytenoids are smaller than in the males.

\section{Postcranial Osteology}

Axial skeleton (Fig. 1C)

The vertebral column is composed of eight procoelous presacral vertebrae, the sacrum and the urostyle.

The vertebrae are imbricated. The relative length of the transverse processes is variable, but most specimens have the pattern: III $>$ IV $>$ V $=$ VI $=$ VII $=$ VIII $>$ II. Ventrally, the relative lengths of the vertebral centra are: $2<3<4=$ to the rest of the vertebrae. The neural arch of each vertebra has a well-developed dorsal ridge, and a pair of parasagital processes extends laterally. The diapophyses of the vertebrae 2, 3 and 4 are expanded.

The atlas is not fused to the adjacent vertebra. The atlas may be or may not be dorsally divided. The centrum of the atlas, in ventral view, is wider than the other vertebrae.

The cotylar arrangement of the atlas resembles a Type II arrangement described by Lynch (1971). The cervical cotyles are semilunar in shape and are oriented lateroanteriorly. The intercotylar region is slightly concave.

The moderately dilated sacral diapophyses are oriented toward the back, and are ovoid in cross-section.

The ilio-sacral articulation is type II B as described by Emerson (1982). There is a mineralized sesamoid element between the ilio-sacral articulations. The sacral-coccygeal articulation is bicondylar.

The urostyle is cylindrical, with a well-developed dorsal spine, and an anterior protuberance. It is not fused to the sacrum. The dorsal ridge is higher anteriorly and reduces its height posteriorly.

Pectoral girdle (Fig. 1D). The girdle is arciferous. The omosternum is cartilaginous and posteriorly mineralized. The distal end is expanded. The anterior expansion is shorter than the xiphisternum, and is fan-shaped.

The episternum is cartilaginous and stick-like and is slightly expanded posteriorly. 
The mesosternum is ossified, and the anterior end is cartilaginous and mineralized. It is simple anteriorly, but with a mid groove. The edges are convergent backward to the middle of its length, and from this point continue parallel to each other or, in some specimens, are slightly divergent.

The xiphisternum is cartilaginous, expanded and mineralized anteriorly. In some specimens it is longer than wide but in others it is wider than long. It is semicircular or trapezoidal with curved posterior edges.

The procoracoid is present and extends to the level of the acute extremes of the clavicles, such that the clavicles do not touch each other.

The epicoracoid is cartilaginous with the anterior and inner lateral edges very mineralized. From a ventral view, the right overlaps the left. The pectoral fenestra is wider than long, rectangular-shaped, with the principal axis in a transverse orientation to the column. The inner margin is concave; the outer is extremely narrow. Each one is anteriorly bordered by the procoracoid cartilage, medially by the epicoracoid cartilage, and posteriorly by the coracoid. The epicoracoidal horns are present.

Each clavicle is curved, bow-shaped, with the anterior side concave. The glenoid end of the clavicle is expanded dorsolaterally into a wedge-shaped process that articulates with the pars acromialis of the scapula. The inner ends are acuminate and do not touch each other because of the interposed procoracoid. The clavicles do not reach the glenoid fossa.

The scapula is rectangular-shaped. The anterodorsal portion of the scapula is composed of a posteriorly convex plate, the pars acromialis, whereas a posteriorly concave plate, the pars glenoidalis, represents the posterodorsal part. The pars acromialis is larger than the pars glenoidalis. The area of contact with the suprascapula is mineralized. The joints with the upper portion of the pars glenoidalis and clavicle, and the inferior portion and coracoid are very mineralized.

The coracoid is subrectangular, the ends are distally expanded.

The glenoid cavity consists of the scapula and the coracoid. A mineralized element, internally and externally visible, is between the scapula and the coracoid. Generally the glenoid cavity is not bordered by cartilage.

Suprascapular cartilage. The outer edge is cartilaginous and mineralized. In some specimens it has an obvious triangular projection on the outer anterior portion, just forward of the superior spur of the cleithrum.

The cleithrum is very mineralized, and is continuous with the suprascapula. It is an ossified and bifid lamina, with the posterior ramus shorter or equal to the anterior ramus. On the upper side it has a ledge forming a longitudinal crest.

\section{Forelimb and manus}

The anterior half of the humerus in males has a very developed humeral crest. The distal head, the eminentia capitata, is broadly expanded and partially ossified. The glenoid head, the caput humeri, is rounded and slightly compressed. 
The radialulnar has a sulcus intermedius indicated by a shallow indistinct groove.

The radius and ulna are completely fused; the groove in the extremes indicates the junction of the two elements.

Six carpal elements are present, representing the Type C morphology described by Fabrezi (1992): ulnare, distal carpal 5-4-3, element $y$, distal carpal 2, radial and proximal element of prepollex. Interestingly, one specimen had one extra element. A dorsal element sesamoid is between the radial and the radius.

Conical sesamoids are present on the ventral face of the distal epiphysis of the metacarpus, and also at the distal epiphysis of the proximal phalanges of digits IV to V. The sesamoids are either separated or medially fused. The epiphyses of the metacarpus and some phalanges have small lateral projections. Metacarpal calcifications are subquadrangular or sub-circular. The inner metacarpus lacks nuptial excrescences. Males have nuptial excrescence in the inner metacarpal.

Phalanges. The phalangeal formula is 2-2-3-3. The relative lengths of the digits are: IV $>$ II $>\mathrm{V} \cong$ III. The terminal phalanges have a split that defines two lobules, or are terminally knobbed.

The prepollex is present; consisting of three segments in addition to the basal segment; the mineralization of the segments diminish from the base to the distal ends. There are three smaller segments adjacents to the corresponding segments of the prepollex. The prepollex have a nuptial excrescence.

\section{Pelvic girdle (Fig. 1C)}

The pelvic plate is semicircular. The angle between the ilial shaft and the preacetabular expansion is less than $90^{\circ}$. The middle joint of the ilia, that corresponds to the preacetabular area, projects anteriorly like a wedge, but with a rounded border. The ventral edge of the ischium reaches to the level of the ilium. The acetabular half of the ilium and ischium are almost equal. The internal margins of the ilia form a U-shape. The ilial shaft is rounded in cross section. The ilia are firmly united to each other medially and the ischia posteriorly. The pubis is very mineralized, localized as a wedge between the ilium and ischium.

The dorsal protuberance is a drop-shape, normally developed (with its height equal to the dorsal acetabular expansion) or short (with its height lower than the dorsal acetabular expansion). The posterior edge of the dorsal protuberance is slightly inclined. The dorsal crest gradually diminishes in height where it articulates with the sacral diapophysis. The ilial crest is lesser than the ilial height.

\section{Hind limb and pes}

The femur is sigmoid-shaped. Both the caput femoris and the distal head of the femur are partially or totally calcified. 
The tibiofibula is longer or almost equal to the femur in length (Table 1). A distinct sulcus intermedius marks the medial union of the tibia and fibula on the extremes of both sides of the bone. The proximal head is almost equal to the distal head.

The tibiale and the fibulare are widely separated from each other at their midpoint, but both the proximal and distal heads of the tibiale and fibulare are fused. Mineralized, spherical sesamoids are present at the femur-tibiofibular and tibiofibular-tibiale/fibulare articulations.

Three tarsal elements are present (following the nomenclature of Fabrezzi, 1993): element $\mathrm{Y}$, distal tarsal 1 and distal tarsal 2-3. The Y element articulates with the base of the prehallux, distal tarsal 1, tibiale, and tarsal 1. Distal tarsal 1 is the smallest and articulates with: element Y, distal tarsal 2-3, metatarsal I and II and tibiale. Distal tarsal 2-3 articulates mainly with metatarsal III, with metatarsal II and IV, with distal tarsal I and with tibiale-fibulare. There are also 1 or 2 small-ossified round elements present under the tarsals.

The digital phalangeal formula is: $2-2-3-4-3$. The terminal phalanges (digit IV) have a split that defines two lobules, sometimes the other digits end in knobs. Subarticular ossified elements are sometimes present. The distal epiphyses of some phalanges and metatarsals have small lateral excrescences.

The prehallux has three segments, with mineralization that decreases from the base to the external segment.

\section{Discussion}

In this work we found some differences with the observations of Lynch (1971) regarding the osteology of Leptodactylus laticeps. He diagnosed the genus based on its having a type I condylar arrangement, although in the description of this character he states that "the larger species (pentadactylus group) have the condyles less widely separated". In our view, the small separation of the condyles present in L. laticeps resembles type II condylar arrangement rather than type I.

Other characters considered by Lynch (1971) that are useful for identifying the genus but that differ with the ones observed in this work are: rounded sacral diapophyses; nasals not in contact with frontoparietals, and anterior ramus of parasphenoid that reaches the palatines.

In that respect, we found that Leptodactylus laticeps exhibits expanded sacral diapophyses (Fig. 2E); the nasals are contiguous or in contact with frontoparietals (Fig. D); and the parasphenoid anterior ramus may or may not reaches the palatines (Fig. 2A). Lynch (1971) also described the frontoparietal fontanelle as missing. Actually, the fontanelle is present, but is completely covered by the frontoparietals.

It is impossible to determine which characters are autoapomorphic without previous knowledge of the osteology of all the remaining members of the group. Some peculiar 
characteristics in L. laticeps are: occipital condyles located forward in relation to the plane that joins the posterior borders of the quadrates, skull width greater than its length, and tibiafibula almost as large as the femur (Table 1). Actually, the two former characteristics are associated with the name of the species, L. laticeps (from latin: latus=broad, ceps=head), in reference to the general shape of the skull. These characteristics could be important to infer the phylogenetic relationships of Leptodactylus laticeps because they are not widely found in the genus.

Other peculiar characters not previously described are:

a) The pars facialis of the maxilla has an extension which may or may not contact the nasals (Fig. 2C).

b) The maxillary teeth do not usually reach the quadratojugal; in some cases, however, they may extend beyond its tip.

c) The posterolateral projections of the frontoparietal are very prominent (Fig. 2B).

d) The nasals are in close proximity or in contact with each other (Fig. 2C).

e) There is a high number of vomerine teeth (10-17).

f) The tip of the palatines is not sharply pointed (Fig. 2A).

g) The alary processes of the premaxillar exhibit a slight posterodorsal orientation.

It is clear that the degree of homoplasy and polarity of these character states will only be established following a cladistic analysis of the genus. It is expected that they will be useful to resolve phylogenetic relationships, since they are shared with others species within the group but not broadly distributed in the genus. Some characters related to the external morphology and life history of L. laticeps appear to be unique to the species. In contrast, no exclusive skeleton characters have been described for L. laticeps. This fact could mean that the environmental and evolutionary factors that influence the species appear not to be as effective in bringing about unique changes in internal structure as they are in affecting its external morphology.

\section{Acknowledgements}

I thank Ronald Heyer (USNM), Sonia Kretchsmann, Marta Canepa and Sebastian Barrionuevo (FML) for providing the material for this study. I'm grateful to Virginia Abdala and Rafael de Sá for commenting on the manuscript, and Greg Cunningham for his help with the English translation. This study was supported by the National Science Foundation (awards 9815787 and DEB-0342918 to Rafael de Sá and Ronald Heyer) and by Consejo Nacional de Investigaciones Científicas y Técnicas (CONICET), Argentina. 
Cei, J.M. (1980) Amphibians of Argentina. Monitore Zoologico Italiano, 2, i-xii + 609 pp.

Emerson, S.B. (1982) Frogs postcranial morphology: Identification of a functional complex. Copeia, 1989, 603-613.

Fabrezi, M. (1992) El carpo de anuros. Alytes, 10, 1-36.

Fabrezi, M. (1993) The anuran tarsus. Alytes, 11, 37-76.

Frost, D.R. (2004) Amphibian Species of the World: an Online Reference. Version 3.0 (22 August, 2004). Electronic Database accessible at http://research.amnh.org/herpetology/amphibia/ index.html. American Museum of Natural History, New York, USA

Heyer, W.R. (1979) Systematics of the pentadactylus species group of the frog genus Leptodactylus (Amphibia: Leptodactylidae). Smithsonian Contributions to Zoology, 301, 1-43.

Heyer, W.R. (1995) South American rocky habitat Leptodactylus (Amphibia: Anura: Leptodactylidae) with description of two new species. Proceedings of the Biological Society of Washington, 108, 695-716.

Heyer, W.R. (1998) The relationships of Leptodactylus diedrus (Anura, Leptodactylidae). Alytes, 16, 1-24.

Heyer, W. R., De Sá, R.O. \& Camargo, A. (2003). Leptodactylus y Vanzolinius, son géneros monofiléticos de ranas?. Repercusiones en filogenia y biología. Resúmenes del VI Congreso Latinoamericano de Herpetología, Lima, Perú, 61 pp.

Larson, P.M. \& De Sá, R.O. (1998). Chondrocranial morphology of Leptodactylus larvae (Leptodactylidae, Leptodactylinae): Its utility in phylogenetic reconstruction. Journal of Morphology, 238, 287-305.

Lynch, J.D. (1971). Evolutionary relationships, osteology, and zoogeography of leptodactyloid frogs. Miscellaneous Publications 53, 238 pp. University of Kansas. Museum of Natural History.

Mccranie, J.R., Wilson, L.D. \& Porras, L. (1980) A new species of Leptodactylus from the could forests of Honduras. Journal of Herpetology, 14, 361-367. 